\title{
Towards Higher Ground
}

\section{Transforming Language Labs into Language Centers}

\author{
John Angell \\ Francophone Studies, University of Louisiana at Lafayette \\ Stayc DuBravac \\ Modern \& Classical Languages, Literatures, \& Cultures, University of Kentucky \\ (formerly of Florida Atlantic University) \\ Margaret Gonglewski \\ The Language Center, The George Washington University
}

\section{Introduction}

Many institutions-including the three discussed in this article-have joined a recent trend to change their "language laboratories" into "language centers" (Garrett, 2003; Liddell \& Garrett, 2004). While the name change is straightforward, transforming the language laboratory and its attendant paradigm into a center, with its expanded mission, can be a slow, recursive process. This broader change represents a reconceptualization of what it means to acquire a language and of how technologies and media can best support this vision. Student-centered, content-based, and contextualized communicative tasks have supplanted more traditional methodologies of guided repetition of forms in the classroom, but the language lab construct has resisted similar evolution. That resistance occurred in the three institutions where the authors of this article inherited the mission of delivering the coup de grâce to the shopworn lab paradigm and facilitating the integration of a new one.

To be sure, as Garrett (2003) and others have pointed out, many labs have been renamed and their potential uses significantly transformed by digital technologies, yet there is evidence to suggest that lab-related uses of these facilities linger on in the choices that stakeholders-students and faculty-tend to make (IALLT, 2006). This paradigmatic hangover persists despite persistent calls for constructivist and integrative alternatives (Liddell \& Garrett, 2004; Warschauer, 2004). The job of the center director entails articulating these alternatives on a daily basis, in a sense translating them into accessible and practical terms. Indeed, teaching materials and practices have evolved over the past twenty years to incorporate student-centered and task-based pedagogies that provide an exploratory, interactionist dimension 
consistent with much second language acquisition (SLA) research and theory (Shrum \& Glisan, 2005). At the same time, theory- and research-based pedagogies in technology-enhanced language learning (TELL) have moved from an emphasis on behavioristic and controlled applications towards a more constructivist integration of technology (Liddell \& Garrett, 2004; Liu, Moore, Graham, \& Lee, 2003; Spodark, 2005; Warschauer, Shetzer, \& Meloni, 2000). Changes in the technologies themselves have made many of these modifications possible, but their tandem evolution with language pedagogy and, on paper at least, best practices advocated by the profession, do not appear to us to have supplanted uses of technology that would have been familiar to language teachers thirty or forty years ago.

As new directors of labs-cum-language centers with backgrounds in language education and applied linguistics, we accepted these roles imagining that our excitement about cutting-edge applications of technology to language learning and teaching would be shared by colleagues and embraced by students. We have on occasion been puzzled when our innovative ideas, workshops, and informal support to colleagues, center staff, and teaching assistants were ultimately ineffective in promoting alternative practices to the extent that we had hoped, perhaps due to lack of time, knowledge, incentive, or reward. Although we have each experienced successes in shaping how our facilities are used, we have also come to realize that shifts in educational paradigms are necessarily gradual. Such shifts also make visible otherwise tacit divergences in goals, approaches, and expectations as well as philosophical and professional divisions among and between colleagues, administrators, and students. Center directors often find themselves inhabiting a kind of middle ground, the impetus for this article and a circumstance that is relevant to those witnessing similarly complex issues relating to their lab/centers' missions and changes (see especially the IALLT Survey of the Profession: IALLT, 2006; also $\underline{\text { Samuels, 2006). }}$ ).

The sections that follow describe administrative, pedagogical, and practical factors that we find pertinent to the implementation of learning and teaching strategies that are consistent with theory, research, and best practices in TELL. We present portraits of the evolution from language lab to language center at our respective institutions and conclude by discussing strategies for encouraging more pedagogically sound uses of facilities and better integration of faculty and student involvement. The discussion is predicated on the fact that, although multimedia classrooms and student access to high-speed internet connections at home are becoming widespread, many institutions, including our own, continue to fund and use dedicated language technology centers (Lahaie, 2003; Wang, 2006).

\section{Two Paradigms: Language Lab versus Language Learning Resource Center}

The cluster of practices that we have termed the language lab paradigm derives from a highly controlled view of the language learning process and of the respective roles of learner and teacher, materials, and, by extension, media and technologies. Indeed, as Garrett (2003) aptly pointed out, the very term "“language lab"” has come to be avoided by some institutions because of its association with sterile carrels and boring listen-and-repeat exercises (p. 3). The lab paradigm construes the computer, as it did previous technologies, as a practice engine, and the learner as a solitary individual engaged primarily in rote, mechanical practice. Lab-oriented work is intended to help learners avoid error by limiting their focus to particular forms, whether aural or written. Accurate production of linguistic forms, often an end in itself within this paradigm, is emphasized through guided repetition and other convergent exercises, fostering an implicit view of the possibilities of learning, knowing, or using a language that does not encompass such domains as creativity and language play, spontaneity, or exploration. The lab approach is fundamentally technology-centered and defines the learner and the 
learning process narrowly: It fits this solitary learner with the technology and the arrangement of the space rather than the other way around. It is consistent with time-honored drilling methods and with a teaching approach in which accuracy supersedes fluency and form routinely trumps meaning or context. This approach is still more prevalent than more fluid, open-ended uses of technology, despite a growing body of research indicating that mechanical drills do not facilitate the development of explicit or implicit knowledge (Aski, 2005, p. 333).

The persistence of this paradigm, so often chosen over available alternatives (Egbert, Paulus, \& Nakamichi, 2002), is robustly supported by a plethora of language learning software and hardware, electronic workbooks, course management systems (CMSs), and foreign language textbooks' companion websites that follow the dominant pattern. In addition to being perpetuated by these resources, lab-style practices hold appealing managerial advantages for over-worked teachers responsible for multiple large classes: Grading is often automated, and learners can be guided through computer-based drills while teachers tend to other responsibilities. Learners can receive automatic feedback from so-called "interactive" exercises and e-mail their results to their teachers, permitting a form of automated self-correction that saves teacher labor and ostensibly supports learning. As students complete assignments, teachers can easily gauge which linguistic forms pose significant problems and which do not. Like pre-communicative teaching and testing practices, these uses of technology ultimately offer a safety zone for students and teachers alike, in which discrete linguistic forms are the essence, "utterances" are limited and either right or wrong, and success is, or at least appears to be, objectively and easily measurable.

The appeal of guided practice and electronic workbooks is that they are convenient and risk free precisely because they do not typically entail significant social or cognitive investment. Additionally, they are already complete, integrated, and accessible to all students and instructors. Finally, many learners generally enjoy the concrete and predictable nature of these activities. Some have noted that these activities may contribute to learning by raising learners' consciousness about language forms through closely guided practice (Lee, 2000; Richards, 2002). Our view is that these tools, however useful, are not sufficient in and of themselves and, most importantly, they do not optimally capitalize on pedagogical and technological resources that are available to our colleagues and their students. Furthermore, in construing learners as isolated individuals, the lab approach does not capitalize on the powerful resources unleashed by participation and membership in on-line learning communities (see Kern, Ware, \& Warschauer, 2004).

The alternative "language center" paradigm is consistent with communicative language teaching as it has evolved over the past twenty years and, more recently, with a constructivist, social-interactionist

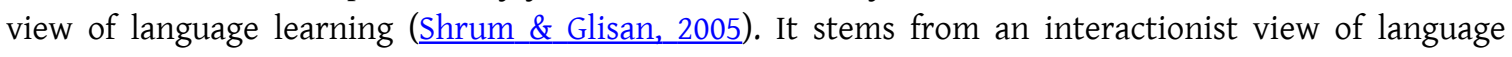
learning that is richly supported by SLA theories (see for example Iohnson, 2004; Mitchell \& Myles, 2004), the literature on TELL (Chapelle, 2001; Hubbard, 1996; Luke, 2006) and the technologies themselves. Meaning and form are evoked within the context of authentic tasks and texts (Hall, 2002). This model encompasses, but goes significantly beyond, language practice and reading and writing; it fosters development of other literacies-cultural, critical, computer, information, geographic-that are important dimensions of academic language learning and teaching and that complement students' educational experiences in other subject areas (Gonglewski \& DuBravac, 2006; Kern, 2000; Warschauer. 1999). Practices associated with the language center model capitalize on digital and especially web-based technologies and resources, envisioning the lab as a point of access to vast cultural and linguistic 
resources as well as information. Most importantly, they focus on the concept of community, to the extent that the computer is in effect a window on two- or multiple-way communication, cultural exploration, and participation and membership in learning or target communities (Salaberry, 1996; Warschauer, 2004). Learners are actively engaged in reflective and exploratory practice, receive nuanced feedback that varies according to the task, and instead of an emphasis on mechanical types of activities that focus on memorizing forms, the learners, or rather community members, are at the center of this orientation.

In general terms, the paradigm shift described here has of course had implications for many institutions aside from-but decidedly similar to-language centers. Libraries are facing analogous revisions, finding themselves in the familiar position of having to constantly reevaluate their services to meet the changing needs of their service population and continuing in the struggle to define themselves as more than a repository for books, particularly in light of the technological innovations essential to users in this information economy and society (Farkas, 2007, p. 50). Article titles in journals of library and information science point directly to the kind of evolution described in this article, both in terms of the apparent necessity of changing with the times and the work to make those changes, e.g., "Re-defining the library" (Brindley, 2006), "The evolving library" (Farkas, 2007), "What librarians can learn from gamers" (Levine, 2006), and "Getting up to speed" (Houghton-Jan, 2007). Approaches taken by libraries on issues such as innovative online (offsite) services, staff training in technology, etc., can provide valuable insight into possible solutions for language centers, and we can only benefit from interdisciplinary discussion and exchange.

Much like the approach many libraries have taken to address changing user needs and incorporate technological advances, language centers can provide an online "space" to extend its services and thereby promote or enhance communicative approaches to language learners. Communicative uses of electronic media consistent with the language center paradigm include the use of both synchronous and asynchronous CMC such as discussion tasks using e-mail, chat, on-line forums, MOOs, Usenet, or CMS discussion boards. Learners also read, participate in, or create target language/culture forums, blogs, on-line journals, and wikis. They engage in web-based research on either a small or large scale: Small-scale, focused explorations of target culture websites include webquests that can be accomplished in one to three class periods (see Dodge, 2001); on a larger scale, learners collaborate in conducting project-based learning or thematic research that they summarize and present to classmates using presentation software such as PowerPoint, i-Movie or through the creation of web pages or blogs (see e.g., Babanoury, 2006; Ducate \& Lomicka, 2005; Gonglewski \& DuBravac, 2006). CMSs such as Blackboard and Moodle can also support the language center paradigm, if they are used to bring students together to collaborate and speak rather than merely for their ability to deliver documents and individualized tests that give automatic feedback.

The language center paradigm described here is conceived as a substantive enrichment of classroom learning and a considerable upgrade of the traditional lab in that it not only capitalizes on technology but exploits the physical space of the language center. To this end, the center's space should be creatively and flexibly arranged to encourage meaningful communicative interaction in the language rather than serving the sole purpose of housing technology and allowing for solitary human-to-computer interfacing. The physical language center should enable different modes of interaction, ranging from small-group work on web page construction to language tutoring, while offering print resources as well as computer- and media-based technological resources such as online, interactive dictionaries, and video 
and audio facilities. It is our belief that the transformation to a language center paradigm does not necessarily exclude uses of technology and treatment of space associated with the lab paradigm, but rather integrates them within this broader social and intellectual context. However, as previously stated, our experience indicates that learners and their teachers often unconsciously choose lab uses over more exploratory and creative uses of the available technological resources.

The constraints, such as limited time, lack of incentives or technical support, that slow the integration of technology by language faculty have been abundantly documented in the literature (see Spodark, 2005, for a discussion). Instructors teaching several large sections, teaching assistants, or senior colleagues who sometimes teach lower level language classes understandably find it convenient to use electronic workbooks, for example, or have their students complete listening exercises when they use the facilities. It has also been largely apparent that the lab paradigm encourages the use of the facilities only for those enrolled in beginning-level language courses, whereas the center paradigm promotes various uses of technology and other center resources throughout the language curriculum.

\section{Lab to Center Evolution: Three Cases}

How does one attempt to develop and manage a language center that addresses the issues the paradigm shift entails? What are the best ways to influence or model practices consistent with the center paradigm? In the sections that follow, we address these questions by offering brief portraits of the on-going evolution from lab to center at our respective institutions: the University of Louisiana at Lafayette, Florida Atlantic University, and the George Washington University.

\section{From Language Lab to Language Resource Center at University of Louisiana at Lafayette}

Upon my arrival at the University of Louisiana at Lafayette (ULL) in 2003, the conversion from a cassette-based lab with a broken central console, housed in an elevated glassed-in booth, to a computer-based facility was half-complete. The Department of Modern Languages in this medium-sized regional institution consists of a program in Francophone Studies (the only program offering graduate degrees) and undergraduate Spanish, German, Latin, and ESOL programs. Given otherwise modest resources, the Department has an unusually spacious, well-lit language lab/center that an initial visit confirmed was chronically under-utilized. Most instructors were still using audio-cassettes, and the majority of the 30 remaining audio carrels did not work. In fact, most of the lab's use involved copying cassettes for students enrolled in the beginning courses in French, German, and Spanish so that they could complete workbook audio assignments, and few classes ever used the sleepy, almost moribund facility as a group. The placement test was a 1968 copyright cassette-based exam (now replaced through generous funding from the university with a web-based model that appears to be functioning well). Some software (Rosetta Stone) was installed in the already aged i-Macs but was largely unused. The then-lab lacked a director, and an intricate schedule ensured staffing by undergraduate work-study students and graduate TAs fulfilling office-hour requirements. With expert technical support, in-house grants, and a few more second-hand computers, we were able to replace the remaining carrels and the console with additional workstations and to arrange them into two zones, a classroom area and a pod of individual computers for individual use. I spent weekends dismounting the old carrels and cassette modules, dragging them into the corridor to be salvaged and revealing a luxuriously large space that we arranged with clusters of computer tables as well as a lounge and conference area. We preserved the dozens of brightly colored, wheeled stenographers' chairs that furnished the carrels and have now found other 
uses for them throughout the center. A ceiling-mounted projector, wall screen, and audio system, a wheeled whiteboard, composition software for Spanish and French, an audio server, and system and memory upgrades have multiplied the potential uses of the computers and classroom space, if not uniformly its actual use. We also scrounged furniture for the lounge, a battered sofa and coffee table, and several large tables for the conference area.

The gradually redesigned and renamed Language Resource Center continues to be referred to by many faculty and students as the "lab," even after four years. Nonetheless, there has been progress. Language club murals embellish many of the walls, as well as student project exhibits, and a collection of donated dictionaries, magazines, and reference materials have made the space more multi-functional and student-centered. Food and drink are allowed in the lounge and conference area. At any given time of the day, there is tutoring, a class, and students working on group projects while others work at the workstations, and the center now serves all students and languages at one time or another during the semester. Use by individual ESOL and Latin students has increased, and a few faculty bring intermediate-level classes to the facility on occasion. Many lower-level language classes hold regularly-scheduled class meetings in the LRC, their meetings enriched by a grant-funded, console-based unit that controls a VCR, a DVD player, an enhanced sound system, wall-mounted screen, and a new projector in the classroom area. Some of the teaching assistants have developed their own ways of using the LRC resources, particularly the projector and audio system, for music, student presentations and screening films. Students also routinely use the work-tables and lounge area. However, teaching assistants once again show a marked tendency, in the absence of consistent reminders and modeling, to revert to more mechanistic, individual use of the companion websites and language drill sites. Students have proven curiously reluctant to work in pairs or groups at a single workstation as well, often exhibiting a tacit preference for a test-like environment with respect to technology use and choosing web-based flash cards, for example, over a video clip or a web search for press articles. Some faculty colleagues continue to choose to remain in the regular classroom during their assigned center meeting times or to send their students individually to complete on-line electronic workbooks or listen to digitized audio-recordings.

At the beginning, I organized or offered several workshops in using Blackboard, Moodle, the Internet, and other resources, but they were sparsely attended except by teaching assistants, so I offer fewer of them now. As a new faculty member, I quickly realized that some senior colleagues were on principle opposed to using the center's resources, so I have focused on interactions with those who do, some of whom are willing to conduct workshops to share their expertise. I also conduct orientations to the center for all classes in French and any others who request it. These orientations offer an important opportunity to promote and model alternative uses of the center, but they occur only once each semester. Weekly meetings of instructors of each level of French provide further opportunity for sharing of ideas for enhancing instruction that often incorporate the LRC. Individual assistance and suggestions, as well as regular calls to colleagues for requests for software during the grant cycle, have borne some fruit and resulted in a bit of increased traffic, but the Spanish program adopted a Quia-based workbook and their classes no longer use the LRC. As director of the French language program, largely taught by TAs, I am able to exert greater influence through methods instruction, modeling, and integration of projects into the syllabi, resulting in what I consider reasonably sound and occasionally inspired uses of the LRC resources and facilities for projects, presentations, performances, and other gatherings as well as for web exploration and other classroom uses. 
The current situation seems relatively static with respect to the other languages' use of the LRC other than occasional drop-ins by individual students. Our center has no line-item budgetary support, so funding comes primarily from competitive university technology grants based on student technology fees. Even paper and office supplies are acquired mostly through scrounging. We do envision expanding the appeal of the center to upper-division literature and culture faculty and to Latin and ESOL, as well as offering more technology support services to faculty and teaching staff as funding and staffing allow. Beyond acquiring updated and improved technologies through additional grants, finding a less-battered sofa, and stocking the coffee table with language-related magazines and publications while seeking to model innovative uses of the available resources, it is a continual challenge to find ways to encourage colleagues and instructors of other languages and higher levels to use the LRC more creatively or to greater advantage. I do believe that the paradigm shift is occurring at ULL, but that I am probably too close to it on a daily basis to observe it, and at the very least the center is serving the majority of language students for the purposes that they and their instructors choose. Nevertheless, as will become evident later in this discussion, my co-authors and I have discovered several general yet concrete strategies to further the lab-to-center transformation beyond a mere name change.

\section{The Foreign Language Media Center at Florida Atlantic University}

The name of the Foreign Language Media Center (FLMC) at Florida Atlantic University (FAU) had changed in 1997 prior to my arrival in 1999. Nonetheless, it was, and still is, against my unremitting protests called the "Spanish Lab" by many students despite the fact that the department includes French, German, Italian, and Linguistics faculty; all of whom use the center throughout the semester. Each semester, over 3,000 graduate and undergraduate students enrolled in four different languages and linguistics used the three-room center. The center received regular support from the Dean for replacing and servicing hardware and software, and the department Chair was highly supportive in providing additional funding for software updates and new purchases. Staff consisted of graduate students in the various languages, which allowed close supervision and coordination among language sections; however, most center activities were not generally in line with the language center paradigm as described earlier in this article.

One of the central themes of the change of the FAU facility from lab to center was a redesign of the space to enable a shift from a technology-centered space to a student-centered environment in which technology was a tool rather than the sole focus of activity. The original design included small cubicles with two computers per cubicle that were not conducive to collaborative interaction. Furthermore, it was not welcoming to students during non-required time (students were required to participate in lab activities 30 minutes per week). The shift from lab to center for the FLMC included two concurrent approaches for augmenting human interaction in the center: 1) increasing the numbers of students in the center during non-required time, and 2) shifting the space from an area where undergraduate students merely complete specific assignments for their classes to a meeting place where students from all languages and levels interact, work on projects, and participate in the culture of being a language major.

One simple method to encourage students to interact with each other more was to provide two large tables in the center of the rooms where they can study, talk, or share work. The availability of non-technology resources, such as paper dictionaries, magazines, and newspapers also helped improve human interaction. These tech-free areas provided an arena for social development around the 
computers and resulted in more study groups, more tutoring, more use of the computer as an occasional language resource instead of as a task-master or drill instructor, and more student time spent exploring target language/cultures in collaboration with others. Shortly after the addition of the tech-free area, students formed two new clubs (Spanish and Linguistics) and both organizations use the space on a regular basis. Food was allowed at these non-tech areas, and additional fringe benefits for the staff encouraged them to be available in off-duty hours. These fringe benefits included a break room with such scavenged comforts as a couch, a refrigerator, a microwave, a coffee maker, in addition to use of the FLMC after hours and on weekends.

The staff was composed of first-year teaching assistants (five hrs/week) and graduate students in linguistics ( $20 \mathrm{hrs} /$ week). The department chair demonstrated true vision by negotiating a course release for all first-year graduate students so that they could work in the center for five hours per week. The time spent by the graduate students in the center benefited both the students and the linguistics program by enabling them to form a cohort of teaching assistants while becoming familiar with the available technology and resources. The staff served as tutors and language resource persons, permitting them to become aware of what their students were doing when they assigned work to be completed in the center. The graduate students in linguistics, the "full-timers" who worked 20 hours per week, served as assistant directors and proved very capable of managing the time schedules of the staff, scheduling room usage, and repairing equipment. Most importantly, however, they functioned as language resources in all of the languages supported by the center, particularly the less commonly taught languages.

The center deemed five machines as developmental machines. The developmental machines contained additional software and peripheral hardware that enabled students to digitize audio and video, scan documents, and generate online forms and activities. This feature of the center encouraged staff and instructors to play with the available resources to create, enhance, or better organize their courses. These developmental machines also provided a repository for good activities and a meeting point where graduate teaching assistants shared pedagogical and management ideas for the classroom.

In another one of the rooms, we pieced together a pseudo-surround-sound system using the projector, a DVD player, and several sets of rewired computer speakers. The room could be reserved for class meetings and became a much-appreciated space for student presentations, film courses, and film nights offered by the French \& Spanish honor societies.

Another method of making the Foreign Language Media Center more welcoming was to provide areas where students could exhibit their work. On a rotating basis, instructors from all levels were encouraged to allow their students to post their work on the walls of the FLMC. Although at times this practice created a somewhat chaotic scene on the walls, it seemed beneficial to those in the lower division courses in providing examples of expectations for future courses. In turn, I believe that it produced a sense of curricular articulation for majors and minors and helped guide expectations for future courses.

Students, however, were not the only variable in the shift from lab to center, and as their presence increased, it became more obvious that instructors needed a vision of how a center was more than a lab. Instructors were not taking advantage of the computer resources available to them because of a reported lack of awareness of possibilities, and limited availability for training. The center director or members of the staff invited individual instructors to come to mini-classes on specific topics offered by the lab staff 
each week that ranged from 15 minutes to an hour. Using the developmental machines mentioned above, I trained the staff how to teach particular topics (Blackboard, Quia, TELL ME MORE, video, audio, online testing, to name a few); the staff in turn taught the weekly mini-classes. Individual instructors were also invited to share their expertise. In some cases, I discussed with certain professors what they might want to do in their classes, identified the necessary technology, and encouraged members of the staff to set appointments during the office hours of certain professors to gain their full attention. These mini-courses often turned out to be one-on-one training sessions for individual faculty.

In many cases, instructors were excited to take the time to learn new technologies and explore possibilities for their courses. A kind of critical mass of activity began to occur in the center at a certain point. The interaction between the center's staff and the professors not only assisted everyone to develop technology applications for courses and thereby provided more possibilities for the students in the center, but it also facilitated communication among professors and staff, yielding a view of themselves as stakeholders in the success of the center. Finally, I noticed that colleagues began to use the term Foreign Language Media Center rather than Spanish lab despite the clumsy name, and that they began to seek ways of using the center for their upper division courses.

\section{Language Lab to Language Center at The George Washington University}

The Language Center at the George Washington University (GWU) was founded in 2004 with a mission to provide resources and services (pedagogic, technical, grant enabling, and programmatic) to ensure the highest caliber language teaching and inquiry for students, faculty, departments and programs that form the GWU community. Just one year previously, the Dean of the College of Arts and Sciences charged a study group composed of faculty and staff from across the university to develop a plan for a center that would contribute to excellence in language teaching, improve student learning of languages and cultures, help increase research activity, and attract external funding to support language research. Based on the group's extensive recommendations, the new Language Center came into being. It is administratively separate from the three language departments at GWU: Classical and Semitic Languages and Literatures, East Asian Languages and Literatures, and Romance, German, and Slavic Languages and Literatures. Eleven language programs currently profit from the Language Center's services: Arabic, Chinese, French, German, Hebrew, Italian, Japanese, Korean, Russian, Spanish, and the English for Academic Purposes program (formerly English as a Foreign Language), which is housed within the Language Center. The Language Center serves approximately 1,500 undergraduate students enrolled in language courses each semester at this private university in the center of the nation's capital.

Prior to the founding of the Language Center, language faculty and students were served by the "Language Lab," which focused exclusively on technological support, i.e., portable equipment, media duplication and conversion, two classrooms with turnkey systems, and one computer lab for independent student work. That the Language Center was to evolve from this pre-existing entity was, in some ways, a blessing. The new Language Center immediately inherited the old lab's three classrooms and an office suite, including a small recording studio. Some of the technological infrastructure was still useable and basic funding, through an existing fee and budget structure, was already in place. There is little doubt that starting from scratch would have slowed the process of organizing the Language Center and its staff (initially the director, executive aide, and a handful of student workers) and of moving forward with its mission. There were also disadvantages, however, to starting within the infrastructure of the old lab. Within the first weeks as director, I was confronted with a vast, necessary clean up of 
outdated technology (from filmstrip kits to Jaz drives) as well as neglected office management issues that included a lack of record keeping of inventory. At a point when I had hoped to be purchasing state-of-the-art technology to address the new mission, I found myself purging a set of rooms filled with inherited, obsolete equipment. Now, three years later, the transition from lab to center is well underway, with evidence that the center paradigm is being gradually, if cautiously, accepted by some and fully embraced by a few, and the "language lab"-both in name and construct-is increasingly a thing of the past.

As at FAU and ULL, a primary aim in the change from lab to center at GWU was a more learner-centered approach, in which technology and layout facilitate communication rather than replace or even impede it. This new paradigm has implications not only for the kinds of technology I chose for the Language Center but also for how the physical space was rearranged and for how the student staff was hired. One of the most valuable changes was transforming an inflexible space into one that supports a variety of communicative activities facilitated, where appropriate, by technology. The old "Language Lab" had two classrooms with turnkey systems featuring cassette recorder-equipped desk rows, linked to a teacher console at the front of the room. While new equipment had been added (e.g., a computer with LCD projector and a region-free DVD player were installed), the physical set-up-and thereby the interaction in the class-remained fixed because of the heavy, immovable desks, wired and nailed together for the purpose of the turnkey system, which had not been used, let alone updated, in years.

To increase adaptability, the old systems were removed and replaced with tables that can be rearranged to accommodate partner and group interaction, or collapsed and put aside to accommodate more dynamic interaction, such as foreign language poetry slams, foreign language game night, or aerobics in Spanish. Flexibility was an equally important factor for the technology in the new Language Center. For this reason, I oversaw the purchase of a large supply of PC laptops with wireless access to the newly installed hub in the adjacent media room, opening up the community of language learners beyond the individual or even the class to the entire world of the target language cultures. To meet similar learning goals, I managed the purchase of several digital still and video cameras, along with iRiver personal audio recorders, which faculty now regularly sign out for projects in class as well as over the summer to record materials during travel abroad. With materials in hand, instructors can attend one of the Language Center's hands-on workshops to learn how to use audio and video editing programs and upload the finished product to a web page or a CMS.

Because the former lab's focus was technology, student workers were hired solely based on their technical skills and interests. These "Lab Aides," mostly graduate students from engineering programs, interacted primarily with the computers, rather than with students. Again for the purpose of creating a broader focus on interaction and language development within a community, I increased the student staff from five to twelve and changed the job description. Students were hired who demonstrated some fluency in at least one foreign language and an interest in the ways that technology can support others to develop fluency. Indeed, "Language Center Assistants" are first and foremost language resources themselves, assisting with the language(s) in which they are fluent; language support outweighs their technical support responsibilities. The goal is not to disregard or ignore technological skills, but rather to bring language back into the center and to stress how technology plays a crucial supporting role in this redefinition of the Language Center. Tutoring takes place within the Language Center's "Media and Language Practice Room" (formerly just "the lab"), where the staff and students have access to print materials such as picture dictionaries and magazines, as well as games, films, and instructional software 
on the 40 computer stations networked to our dedicated server. The assistants facilitate the use of language learning software such as Auralog's TELL ME MORE that provide exploratory learning and language play through vocabulary games, etc.

In addition to the spatial, technological, and staffing changes in the center, outreach to language departments has been crucial to the ongoing success of the Language Center and its programs. Thus far, faculty involvement includes attending technology workshops, using Language Center classrooms and equipment, and benefiting from funding for professional development. This level of involvement could prove fleeting, however, and does not provide a strong enough link between the Language Center and the departments and their faculty. I have sought to nurture well-defined relationships-with relevant tasks and rewards-that help colleagues feel committed to the long-t-erm existence and success of the Language Center. Specifically, I have invited language faculty to be featured speakers in the new series I created, entitled "Language Teaching Innovations." I established a Language Center Fellowship (described later in this article), through which we gained our Technology Specialist, a language faculty member now regularly committed to assisting with workshops, technology purchases and maintenance. I created a faculty group called "Language Center Liaisons," comprised of all ten language program directors. These departmental ambassadors are responsible for relaying information between their programs and instructors and the Language Center staff. Regular meetings also serve to bring this group together to create a community among language faculty who, though spread across three separate departments, have similar interests and needs. Their input on equipment purchases and feedback on program planning is critical to both the actual and perceived success of the Language Center.

Careful thought was given to ways of extending the Language Center's reach beyond the limits of its physical space, and top priority went to designing a web page. At a minimum, the web page would provide basic information about the new Language Center, its mission and staff, as well as day-to-day operations, including the tutoring schedule and a listing of upcoming events linked to the university's online events calendar. More important, the web presence would help to underscore the paradigm shift from lab to center by utilizing that technological resource to link learners to each other and to external resources with the aim of facilitating real-world language use. For example, we developed the Language Exchange, an online database system embedded in our website that allows users to search for another person within the GWU community with whom to practice conversing in the target language. The Language Center website also links students and faculty to the Scola site, where password holders can view multiple channels of television programs from foreign countries. This subscription service, paid for by the Language Center, also offers faculty downloadable video and audio files along with lesson plans, vocabulary lists, and quizzes to accompany specific programs. Because of our website, we are able to serve stakeholders who never set foot in the Language Center.

It is clear that the GWU Language Center has had advantages that many new centers do not. From the beginning the Language Center benefited from the enthusiastic, sustained support of the administration; in fact, the very existence of the new Language Center is owed to the former Dean's vision to better serve GWU's language teaching and learning community. There are sufficient resources to cover equipment and software purchases as well as fund new faculty development incentives. And as each success brings new demands, new levels of support in the form of funding and staffing allow further expansion of the Language Center's efficacy. In its third year, the Language Center was able to bring on board a Deputy Director, a new faculty member whose position is also partially in the Spanish program, and the new Office Supervisor is essential to managing the expanded student staff. However, some of the 
most significant successes so far are traceable not to a dollar amount in the budget but to hands-on work and relationship-building on the part of myself and my staff and have resulted in the development of a strong sense of both community and ownership in the Language Center among the faculty and students who use it.

\section{Facilitating the Shift from Lab to Center: Strategies and Suggestions}

Clearly, building relationships and fostering communication and leadership has been as important in influencing the evolution of our centers as technology, management, or funding. We have each sensed the importance of achieving a "critical mass" of activity surrounding the centers that involves the many constituents and stakeholders to the fullest extent possible. The strategies and suggestions below include both these less formal approaches and more concrete aspects of the design and use of space, education and training of stakeholders, management, and resource-building and outreach. We trust that these ideas will prove adaptable or appropriate elsewhere, with necessary adjustments for local circumstances.

\section{Design and Use of Space}

Our most effective tactics have been those that broaden the use of the centers to support language activities as a whole, rather than reserving use for technology-based events only. Specifically, we have all expanded our centers to include language tutoring and student exhibits, and we have initiated meetings, language club activities, receptions, guest speakers, and other events that indirectly raise the centers' profile in the daily functioning of the language departments. This has also helped to ensure that non-technology materials and spaces are incorporated into the centers. Comfortable furniture, student art-work and projects, magazines, and games make the centers inviting places for language students to meet, and the hardware and software literally become resources that are used as needed. Another effective development is a kind of informal reserve desk that loans materials, books, CDs, or software to students in exchange for their identification cards. Use of this service has skyrocketed since faculty discovered it, and it helps to soften the technology bias of the center.

Organizing a comfortable, well-lit lounge area where food and drink are accepted has helped to ensure that the language students feel a sense of belonging. Exhibiting student language-related work such as posters and artwork has also contributed to establishing that the centers belong to students for any language-related work or play. Finally, we have had success experimenting with language-specific areas in our centers that further provide a sense of belonging and ownership to students of that language. Setting up computer stations with operating systems and software or keyboards set to function in the foreign language creates a virtual immersion experience and contributes to an esprit de corps, particularly among students of less commonly taught languages.

\section{Education and Training}

In addition to offering periodic workshops and inviting successful colleagues to share their approaches, we have found that unconventional, informal, and creative strategies have had some impact on center use. These include establishing drop-by technology office hours during which center directors or staff are available for consultation by colleagues and teaching assistants. One-on-one consultations work well with individuals who are curious enough or motivated enough to come see us and have a general idea of what they would like to do with technology. Mentoring senior colleagues or individuals who have long-established teaching practices is a complex undertaking, and we have found that indirect 
approaches can be effective in preserving positive relationships in departments. A slightly more proactive tactic that has also proven effective is what we term the "minstrel approach," seeking out colleagues on an informal basis in their offices and asking how the center's resources and staff can assist them or making a specific suggestion and offering to follow up with their classes. Initiating such informal, focused contacts may in many cases be our most fruitful strategy for influencing the paradigm shift in center use, but their impact once again depends largely on individual relationships and requires sustained effort on our part.

Another informal approach has been to identify and mentor staff, teaching assistants, and instructors who show an interest in innovation. They then become key sources of ideas for peers or for colleagues reluctant to ask center directors or other colleagues for assistance. Egbert et al (2002) echo this claim that the most common source of new ideas for activities is from peers and colleagues rather than by mandate of a language program director. A similar but more formal tactic, clearly dependent on the availability of funding, course releases, or resource allocation, has been to establish language center fellowships, which enable interested faculty who are named as fellows to work more closely with center constituents and staff as well as encouraging and rewarding innovative integration of technology and resources into their teaching.

\section{Management}

With respect to the management of people and space, each of our directorships differs in administrative structure depending on local specificities, as is the case throughout the profession (IALLT Survey of the Profession, 2006; see also Lahaie, 2003). Our institutions do not, as a rule, provide significant incentives for faculty to innovate without applying for grants, and only the very eager take advantage of these opportunities. Again, improvised tactics tend to work well in the absence of more ample resources. For example, each of us has found ways to provide small incentives and fringe benefits such as food, workspace, or technology support, to faculty who use the center. These opportunities to exchange ideas add energy to the movement toward language center and contribute to the formation of a core of peers and colleagues who can subsequently influence others in an ever-widening circle.

Along similar lines, we have found value in working closely to train staff to be proactive in supporting classes or student groups in solving technical problems and, more importantly, finding more challenging and interesting uses of the resources. We regularly involve our staff in brainstorming sessions about how to better arrange furniture, workstations, lounge areas, or other facilities in order to create a comfortable, useable space. In introducing technological tools, Farkas (2007) suggests, The best way to get everyone committed to a new technology is to involve staff from all levels of planning (p. 50); group involvement also promotes a collaborative and non-exclusive atmosphere. As faculty, staff, and students begin to share and help shape a vision of what can be accomplished in the center, its evolution as a broad-based locus of resources can accelerate.

\section{Resource-building and Outreach}

Building alliances and support across campus has proven moderately successful in our centers, especially when administrative support is strong. In one instance, a multi-disciplinary advisory board has increased the profile of the center and engendered support for its mission as a locus of resources for anything related to language. Collaboration with other labs and computer centers on campus has been fruitful at least in terms of moral support, but each discipline seems to have such a specific vision of how 
technology is optimally integrated into learning and teaching that these contacts tend to be primarily technical in nature. We envision our centers as fundamentally interdisciplinary facilities, but that vision has proven for the most part as difficult to articulate as it is to implement, meaning that the centers struggle constantly to be perceived by outsiders as anything but drab, fluorescent-lit islands filled with machines. Continued outreach and informal tactics designed to enlarge the circle of innovation thus remain important, ongoing areas of activity.

\section{Conclusion}

We have realized in collaborating on the lab-to-center question and in examining our colleagues' experiences in the IALLT Journal and elsewhere that part of the paradigm problem is that technology is considered by many in the profession primarily as a complement to language acquisition as opposed to a set of tools supporting the development of cross-cultural competence or multiliteracy. The centers struggle constantly to go beyond serving essentially as places to do the equivalent of workbooks in teched-out labs. Promoting an alternative vision and thinking globally while acting locally strike us as the principal responsibilities of language center directors. We have learned that accelerating a paradigm shift is a complicated, labor-intensive process but that witnessing the impact of our efforts on the local educational culture can be its own reward. We each seek in our interactions with colleagues reluctant to adopt new practices or administrators who cannot afford in-depth involvement to be non-judgmental and simply to find ways of fostering change that are indirect and positive. Practices associated with what we have termed the lab paradigm are not inherently misguided, they simply are not consistent with either what our facilities can support or what the profession currently advocates as best practice. The stubborn persistence of behaviorist software and commercial materials, the lack of incentives for faculty innovation, subtle resistance to new ways of learning and teaching, and lingering uncertainty about the potential of technology in education all impede these endeavors. Nevertheless, we interpret our directorships at three very different institutions as a mandate to articulate and implement compelling visions of how our centers can enhance classroom teaching while also contributing to university students' overall education as communicatively competent, literate global citizens.

\section{References}

Aski, J. M. (2005). Alternatives to mechanical drills for the early stages of language practice in foreign language textbooks. Foreign Language Annals 38(3): 333-343.

Babanoury, C. (2006). Collaborative company research projects: A blueprint for language, culture, and content learning. The Journal of Language for International Business 17(1): 15-28.

Brindley, L. (2006). Re-defining the library. Library Hi Tech 24(4): 484-495.

Chapelle, C. (2001). Computer Applications in Second Language Acquisition. Cambridge: Cambridge UP.

Dodge, B. (2001). FOCUS-Five rules for writing a great WebQuest. Learning \& Leading with Technology 28(8): $6-9,58$.

Ducate, L. C. \& Lomicka, L. L. (2005). Exploring the blogosphere: Use of web logs in the foreign language classroom. Foreign Language Annals 38(3): 410-422.

Egbert, J. , Paulus, T. \& Nakamichi, Y. (2002). The impact of CALL instruction on classroom computer use: 
A foundation for rethinking technology in teacher education. Language Learning \& Technology 6(3): 108-126.

Farkas, M. (2007). The evolving library. American Libraries 38(6): 50.

Garrett, N. (2003). Language learning centers: An overview. In Lahaie, U. S. (Ed.), The IALLT Management Manual (pp. 1-9). Wheeling, Illinois: International Association for Language Learning Technology.

Gonglewski, M. \& DuBravac, S. (2006). Multiliteracy: Second language literacy in the multimedia environment. In Ducate, L. \& Arnold, N. (Eds.), Calling on CALL: From theory and research to new directions in foreign language teaching (pp. 43-68). San Marcos, TX: CALICO.

Hall, J. K. (2002). Methods for teaching foreign languages: Creating a community of learners in the classroom. Upper Saddle River, NJ: Merrill/Prentice Hall.

Farkas, M. (2007). Getting up to speed. American Libraries 38(6): 54.

Hubbard, P. (1996). Elements of CALL methodology: Development, evaluation, and implementation. In Pennington, M. (Ed.), The power of CALL (pp. 15-32). Houston, TX: Athelstan.

IALLT Survey of the Profession. (2006). The IALLT Journal of Language Learning Technologies 38(1): 15-48.

Johnson, M. (2004). A philosophy of second language acquisition. New Haven, Conn.; London: Yale University Press.

Kern, R. (2000). Literacy and Language Teaching. Oxford: Oxford University Press.

Kern, R. , Ware, P. \& Warschauer, M. (2004). Crossing frontiers: New directions in online pedagogy and research. Annual Review of Applied Linguistics 34(3): 243-260.

Lahaie, U. S. (Ed.) (2003). The IALLT Management Manual. Wheeling, Illinois: International Association for Language Learning Technology.

Lee, J. F. (2000). Five types of input and the various relationships between form and meaning. In Lee, J. F. \& Valdman, A. (Eds.), Form and meaning: Multiple perspectives (pp. 25-42). Boston: Heinle.

Levine, J. (2006). What librarians can learn from gamers. Library Technology Reports 42(5): 60-62.

Liddell, P. \& Garrett, N. (2004). The new language centers and the role of technology: New mandates, new horizons. In Fotos, S. \& Browne, C. (Eds.), New perspectives on CALL for second language classrooms (pp. 27-40). Mahwah, NJ: Lawrence Erlbaum Associates.

Liu, M. , Moore, Z. , Graham, L. \& Lee, S. (2003). A look at the research on computer-based technology use in second language learning: A review of the literature from 1990-2000. Journal of Research on Technology in Education 34(3): 250-273.

Luke, C. (2006). Situating CALL in the broader methodological context of foreign language teaching and learning: Promises and possibilities. In Ducate, L. \& Arnold, N. (Eds.), Calling on CALL: From theory and research to new directions in foreign language teaching (pp. 21-41). San Marcos, TX: CALICO.

Mitchell, R. \& Myles, F. (2004). Second Language Learning Theories. London: Arnold.

Richards, J. C. (2002). Accuracy and fluency revisited. In Hinkel, E. \& Fotos, S. (Eds.), New Perspectives on Grammar Teaching in Second Language Classrooms (pp. 35-50). Mahwah, NJ: Lawrence Erlbaum Associates. 
Salaberry, M. R. (1996). A theoretical foundation for the development of pedagogical tasks computer mediated communication. CALICO Journal 14(1): 5-34.

Samuels, J. D. (2006). The day they gutted the language lab, or J'accuse. The IALLT Journal of Language Learning Technologies 38(1): 49-55.

Shrum, J. \& Glisan, E. (2005). Teacher's handbook: Contextualized language instruction. Boston: Heinle.

Spodark, E. (2005). Technoconstructivism for the Undergraduate Foreign Language Classroom. Foreign Language Annals 38(3): 428-435.

Wang, J. (2006). The changing roles of a language learning center at a residential liberal arts college in the midst of technological development. The IALLT Journal of Language Learning Technologies 38(1): 55-65.

Warschauer, M. (1999). Electronic Literacies: Language, culture and power in online education. Mahwah, NJ: Lawrence Erlbaum Associates.

Warschauer, M. (2004). Technological change and the future of CALL. In Fotos, S. \& Browne, C. (Eds.), New perspectives on CALL for second language classrooms (pp. 3-14). Mahwah, NJ: Lawrence Erlbaum Associates.

Warschauer, M. , Shetzer, H. \& Meloni, C. (2000). Internet for English teaching. Alexandria, VA: Teachers of English to Speakers of Other Languages, Inc. 